\title{
CURSO DE PEDIATRIA PREVENTIVA E SOCIAL II PARA O 5. ANO DA FACULDADE DE MEDICINA DA UNIVERSIDADE DE SÃO PAULO: UM RELATO DE EXPERIÊNCIA DE 15 ANOS
}

\section{Luiza Arthemia Suman Mascaretti*}

\section{Sumário}

Um estudo retrospectivo foi feito relativo às atividades desenvolvidas junto aos quintanistas da FMUSP nos últimos anos cursando a disciplina de Pediatria Preventiva e Social II. A autora relata os objetivos do curso, a metodologia e avaliação do mesmo ressaltando a importância que este tem tido na formação dos alunos, ou seja, ajudando-os a criar responsabilidade diante dos clientes e exercerem Puericultura em nível de 1." linha (atenção primária em saúde).

\section{Considerações Gerais}

O Departamento de Pediatria da Faculdade de Medicina da Universidade de São Paulo exerce suas atividades docentes junto aos alunos desta Faculdade através de três disciplinas principais: a) Pediatria Neonatal; b) Pediatria Clínica e c) Pediatria Preventiva e Social.

A disciplina de Pediatria Preventiva e Social é subdividida em Pediatria Preventiva e Sociall (ministrada para os alunos do $4 .^{\circ}$ ano), Pediatria Preventiva e SociallI (para os alunos do $5 .^{\circ}$ ano), Pediatria Preventiva e Social III (aos alunos do $6 .^{\circ}$ ano).

\section{ANEXO I}

Seriação, denominação, local, créditos-aula, créditos trabalho e horas das Disciplinas de Graduaçåo do Departamento de Pediatria - FMUSP.

\begin{tabular}{|c|c|c|c|c|c|c|}
\hline ANO & NOME (SIGLA) & REGIME & LOCAL & $\mathrm{CA}$ & CT & HORAS \\
\hline $30^{\circ}-1,3 \%$ & $\begin{array}{l}\text { Nutrição - Aplicaçס̃es } \\
\text { Clínicas (MPE-313) }\end{array}$ & Não-Internato & $\begin{array}{l}\mathrm{FM} \\
\mathrm{HC} \\
\mathrm{ICB}\end{array}$ & 01 & 0 & 15 \\
\hline $4:^{\circ}-9,3 \%$ & Ped. Prev. e Social I (MPE-411) & Nåo-Internato & CSE & 07 & 0 & 105 \\
\hline $5 ?-36,0 \%$ & $\begin{array}{l}\text { Ped. Prev. e Social II (MPE-511) } \\
\text { Ped. Clínica I (MPE-521) }\end{array}$ & $\begin{array}{l}\text { Internato } \\
\text { Internato }\end{array}$ & $\begin{array}{l}\text { CSE } \\
\text { I.Cr. }\end{array}$ & $\begin{array}{l}02 \\
05\end{array}$ & $\begin{array}{r}0 \\
10\end{array}$ & $\begin{array}{r}30 \\
375\end{array}$ \\
\hline $6 ?^{\circ}-53,4 \%$ & $\begin{array}{l}\text { Ped. Prev. e Social III (MPE-611) } \\
\text { Ped. Clinica II (MPE-621) } \\
\text { Ped. Clinica VI (MPE-623) } \\
\text { Ped. Clinica Neonatal II (MPE-631) }\end{array}$ & $\begin{array}{l}\text { Internato } \\
\text { Internato } \\
\text { Internato } \\
\text { Internato }\end{array}$ & $\begin{array}{l}\text { DSE } \\
\text { I.Cr./PS } \\
\text { HU } \\
\text { HU }\end{array}$ & $\begin{array}{l}01 \\
04 \\
04 \\
03\end{array}$ & $\begin{array}{l}01 \\
04 \\
05 \\
04\end{array}$ & $\begin{array}{r}45 \\
180 \\
210 \\
165\end{array}$ \\
\hline
\end{tabular}

$\mathrm{CA}$ - crédito-aula $=15$ horas

CT - Crédito-trabalho $=30$ horas

" integra o conjunto de Disciplinas "Nutrição" juntamente com Fisiologia e Medicina Preventiva.

$\mathrm{FM}=$ Faculdade de Medicina

ICB = Inst. de Ciências Biomédicas
$\mathrm{HC}=$ "Complexo Hospital das Clínicas"

CSE = Centro de Saúde Escola

I.Cr. = Instituto da Criança

DSE = Distrito de Saúde Escola

I.Cr./PS = Instituto da Criança/Pronto Socorro

$\mathrm{HU}=$ Hospital Universitário

- Prof. Assistente Doutor do Departamento de Pediatria da Faculdade de Medicina da USP. 
Exercendo há 15 anos, a função de Coordenadora da Disciplina de Pediatria Preventiva e Social II (para alunos do $5^{\circ}$ ano) considero importante relatar esta experiência junto aos alunos durante este período neste curso eminentemente prático.

Cabe um breve histórico dizer que esta disciplina é ministrada em seqüência a Pediatria Preventiva e Sociall oferecida aos quartanistas e é administrada em períodos de 8 semanas consecutivas, onde os alunos comparecem ao Centro de Saúde "Prof. Samuel B. Pessoa" para proceder o atendimento de uma população de crianças de 0 a 14 anos, mais especificamente composta por lactentes e pré-escolares por uma questão natural de maior demanda destas faixas etárias. Nesta ocasião devem promover uma atenção global às crianças procedendo a vigilância do crescimento e desenvolvimento.

\section{Conteúdo Programático}

Durante $044^{\circ}$ ano os alunos recebem informações teóricas a respeito de higiene alimentar, higiene anti-infecciosa, higiene mental, higiene do ambiente físico e de crescimento e desenvolvimento e Ihes são conferidas condições para aprender a fazer anamnese, exame físico das crianças e de realizar uma prescrição pediátrica.

No $5^{\circ}$ ano existem diferenças importantes a serem levadas em consideração:

a) os objetivos cognitivos são os mesmos do ano anterior, pois trata-se de um curso eminentemente prático, ou seja, a programação teórica do Curso de Pediatria Preventiva e Social II é aquela já apresentada durante - 4. ano. Assim sendo são incentivados a recordá-la;

b) os objetivos psicomotores estão relacionados ao atendimento das crianças e deverá ser feito com maior velocidade sem que isto interfira na qualidade do atendimento;

c) os objetivos afetivos referem-se aos aspectos da relação médico/paciente e às vantagens que eles e os clientes têm e suas familias de que esta se desenvolva bem (vide programação oficial com os objetivos explicitados tal qual são oferecidos aos alunos).

\section{ANEXO II}

\section{ANO}

\section{PEDIATRIA PREVENTIVA E SOCIAL II (MPE - 511)}

$$
\begin{aligned}
& \text { Semestres }-\mathrm{IX} \mathrm{e} \\
& \text { Duração }-30 \text { horas } \\
& \text { Créditos }-2 \text { créditos-aula } \\
& \text { Local } \quad-\text { Centro de Saúde Escola do Butantã }
\end{aligned}
$$

\section{1. Área Cognitiva}

Os objetivos intermediários cognitivos da Disciplina Pediatria Preventiva e Social II são os mesmos da Disciplina Pediatria Preventiva e Social I ministrada nos semestres VII e VIII.
O que se pretende é que o aluno, através do atendimento de consultas e do diálogo com os docentes, aprofundem os conhecimentos adquiridos anteriormente, já que não está previsto um programa acadêmico formal para a disciplina de Pediatria Preventiva e Social II.

\section{2. Área Afetiva}

Ao final do programa, o aluno deverá estar capacitado a:

1. Assistir globalmente a criança, considerando-a como um ser físico, mental e social indivisivel;

2. Reconhecer a influência dos fatores ambientais na gênese e evolução dos distúrbios da criança;

3. Desempenhar papel educativo no contato com a criança e seus familiares;

4. Participar do trabalho de equipe para o controle de saúde;

5. Valorizar o controle periódico da saúde da criança;

6. Desenvolver relações empáticas com a mãe e a criança no decorrer da consulta;

7. Minimizar a interferência de fatores sócio-econômicos na comunicação com a criança e seus familiares e

8. Reconhecer as limitações da ação do Pediatra Geral.

\section{3. Área Psicomotora}

Ao final do programa, o aluno deverá estar capacitado a:

1. Realizar a anamnese da criança em 20 a 40 minutos (consulta de primeira vez) e 15 a 20 minutos (consulta de retornol com ênfase nas condições habituais de vida, condições gerais de ambiente físico e psicológico e condições atual de imunização;

2. Realizar o exame físico da criança em 20 a 40 minutos (consulta de primeira vez) e 15 a 20 minutos (consulta de retorno) com ênfase na antropometria, avaliação do desenvolvimento neuropsicomotor, avaliação do estado geral e do estado nutricional;

3. Escrever uma orientação de cuidados preventivos e terapêuticos e

4. Escrever um encaminhamento.

\section{Procedimentos}

\section{a) Junto aos alunos}

Ao chegar ao $5 .^{\circ}$ ano verificamos durante todos estes anos que os mesmos mostram-se um tanto quanto esquecidos no que diz respeito aos aspectos básicos ensinados durante $04 .^{\circ}$ ano, embora tenham atingido os objetivos terminais deste curso, fato que já comprovamos em trabalho anterior (1). Isto não é surpresa e trata-se da evasão natural do conhecimento adquirido de um modo tanto ou quanto rápido e sem estímulos "de reforço". Sabedores disto, temos durante todos estes anos procurado sempre ao recebê-los, acalmá-los quanto a este aspecto já que ao mesmo tempo dizemos a eles que terão de adquirir "maior autonomia diante dos clientes".

Ênfase têm sido dada nestas ocasiões (durante os momentos em que os recebemos) aos aspectos do relacionamento deles com os docentes. Recebemos normalmente 30 alunos durante o período de 8 semanas. Os 
mesmos são subdivididos em dois grupos de 15 alunos que comparecem num período de 4 horas por semana no Centro de Saúde. Neste local dispõe-se de quatro salas para atendimento e, portanto, 3 ou 4 alunos em cada sala atendendo em dupla, ou individualmente (cada dupla de alunos com um cliente). Cada grupo de 15 alunos fica sob a supervisão de três docentes para assistí-los. No momento em que são recebidos enfatizamos a importância deles interagirem com os docentes procurando-os livremente, ou seja, quando acharem necessário.

Nesta ocasião valorizamos a importância disto no sentido deles perceberem também o quanto é importante conhecer a conduta de outros assistentes a respeito de aspectos clínicos tão semelhantes, para adquirir as suas próprias posturas, e, em função disto, declaramos que nunca deverão perder de vista o conceito de atenção à criança junto à sua família inserida em sua comunidade.

Neste mesmo momento procuramos fazê-los entender também que encontram-se exercendo atenção primária em saúde e solicitamos aos mesmos não confundirem isto com "mau atendimento" ou "atendimento superficial".

Enfatizamos a validade de atender bem estas crianças, solicitando o menor número possível de exames, sem que isto interfira na qualidade do atendimento podendo até fazê-lo quando for preciso.

Procuramos dar liberdade aos launos de modo a fazê-los sentir que adestrando-se para atender crianças em seu núcleo familiar, estão também cada vez mais adquirindo habilidades novas tanto no trato com o cliente como também junto aos seus familiares, entendendo as limitações dos mesmos e as de si próprios de modo a exercer um atendimento em primeira linha com "qualidade", ou seja, exercendo Puericultura em nível de atenção primária.

Em todo final de estágio realizamos uma reunião que denominamos "forum" para os alunos avaliarem o curso ministrado, ou seja, avaliação do processo de ensino/aprendizagem. Nessa ocasião os alunos são incentivados a tecerem críticas construtivas livremente com a finalidade de modificar alguma coisa que considerem importante.

Durante todos estes anos temos acatado sugestões procurando modificar aquilo que eles sugerem, que consideram pertinentes e que estejam ao nosso alcance.

A Avaliação dos alunos é feita através de conceito emitido pelos professores, levando em consideração:

1) as habilidades novas adquiridas durante o estágio, tanto psicomotoras como quanto afetivas, junto às crianças e aos seus familiares, ou seja, a melhoria da qualidade do atendimento realizado pelos alunos;

2) maior compreensão das informações teóricas adquiridas no ano anterior;

3) a capacidade de atuar junto à equipe multiprofissional (a do Centro de Saúde e também as outras em níveis de atendimento de maior complexidade como a do Hospital Universitário e também do Instituto da Criança e outras vinculadas à Secretaria do Estado).
As notas variam de 0 a 10 e é feita uma média aritmética entre os conceitos emitidos pelos professores.

\section{b) Junto aos professores}

Temos procurado manter todos os professores cientes dos objetivos do Curso. Quando existem trocas de assistentes procuramos apresentar os objetivos do Curso para novos professores.

Para eles também é importante, a nosso ver ficarem cientes de que à medida que o curso vai transcorrendo os alunos devem estar adquirindo cada vez mais responsabilidade diante dos clientes.

Trabalhamos com dois assistentes ou três por período para nos auxiliar nestas tarefas e que é também instruído a atuar do ièmesmo modo.

Sempre solicitamos que aguardem serem chamados pelos alunos para resolver as dívidas destes, sem no entanto sentirem-se impedidos de supervisionar o atendimento diretamente.

\section{Conclusões}

No decorrer destes anos pudemos verificar que a responsabilidade dos alunos diante dos clientes é crescente com esta metodologia.

Através de reuniões sucessivas verificamos que os alunos durante estes anos realizam o curso demonstrando que gostam e que aprendem bastante.

As queixas foram poucas, sendo na maioria das vezes relacionadas a falta de assistentes, já que o curso foi previsto com atuação de no mínimo 2 a 3 assistentes por período e que por motivos diversos (faltas, mudança de local de trabalho, aspirações diferentes, ausência de vocações, greves etc.) não estiveram presentes. Acham muito bom cbjeto também de discussão em grupo. Fomos selecionando as críticas, interagindo com os professores, estabelecendo prioridades no sentido de corrigir o que estava inadequado. Nem sempre foi e é possível resolver todas evidentemente, já que o número de assistentes disponíveis independe de nossa decisão.

No entanto, algo extremamente importante vem acontecendo, ou seja, os quintanistas daFMUSP têm declarado durante nossas reuniões que sentem cada vez mais segurança ao atender crianças realizando Puericultura. Isto tem sido verificado em todas as turmas no decorrer destes anos. Declaram ainda que cada vez mais sentem-se à vontade para atender crianças com uma meIhor "performance".

\section{Referência Bibliográfica}

1. MASCARETTI, Luiza A. S. ; WESTPHAL, Márcia F.; MARCONDES, Eduardo; CARVALHO, Márcia M. B. de. A utilização do material instrucional e sua influência no aprendizado de Pediatria. Rev. bras. Educ. Méd., 11(1):19-23, 1987.

Endereço do autor:

Rua Prof. Horácio Berlinck, 551 - City Butantã

05505 - São Paulo - SP 